\title{
KEPUASAN LAYANAN IBU HAMIL PENGGUNA PROGRAM BPJS DI PUSKESMAS SE-KOTA BENGKULU TAHUN 2014
}

\author{
Rachmawati, Kosma Heryati \\ Politeknik Kesehatan Kementerian Kesehatan Bengkulu, Jurusan Kebidanan, \\ Jalan Indragiri Nomor 03 Padang Harapan Kota Bengkulu \\ sabrina_kosma1956@yahoo.com
}

\begin{abstract}
With the implementation of BPJS'S programs that replace Jampersal, then patient satisfaction from cost faktors or foundation complete. Patient Satisfaction can be also assessed from the age of mother, education, employment and maternal parity use BPJS'S program. The purpose of this observation is for description the level of mother's satisfaction toward implementation of BPJS'S program in all clinic of Bengkulu city. The design that use is cros secsional with all of population pregnant mother that do examination in all clinic of Bengkulu city amount 115 people's taken with Accidental sampling technic. Level analysis of satisfaction of pregnant mother toward implementation of BPJS based on the comparison of the distribution the patient satisfaction that look from age, education, employment and parity also statistik analysis with Chi Square test. The result of observation was not relation between age, education, employment of pregnant mother toward implementation BPJS'S program in all clinic of Bengkulu city, while parity analysis there is relation of maternal parity toward implementation BPJS'S program in all clinic Bengkulu city. Be expected medical employment can be improve implementation BPJS'S program start from level of primer until the level of sekunder be better than before.
\end{abstract}

Keyword : age, education, employment, preagnant mother satisfaction.

\begin{abstract}
Abstrak : Dengan diberlakukannya Program BPJS yang menggantikan Jampersal, maka kepuasan pasien dari faktor biaya atau pendanaan terpenuhi. Kepuasan pasien juga dapat dinilai dari usia ibu, pendidikan, pekerjaan dan paritas ibu hamil pengguna program BPJS. Tujuan penelitian ini adalah untuk mendeskrpsikan tingkat kepuasan ibu hamil terhadap pelaksanaan program BPJS di Puskesmas se-kota Bengkulu. Desain yang digunakan adalag potong silang dengan populasi seluruh ibu hamil yang periksa di Puskesmas se-Kota Bengkulu berjumlah 115 orang diambil dengan tehnik Accidental sampling. Analisa tingkat kepuasan ibu hamil terhadap pelaksanaan BPJS berdasarkan perbandingan distribusi kepuasan pasien dilihat dari usia, pendidikan, pekerjaan dan paritas serta analisis Statistik dengan uji Chi Square. Hasil penelitian tidak ada hubungan antara usia, pendidikan, pekerjaan ibu hamil terhadap pelaksanaan program BPJS di Puskesmas se-Kota Bengkulu, sedangkan analisis Paritas yaitu Ada hubungan Paritas ibu bersalin terhadap pelaksanaan program BPJS di Puskesmas se-Kota Bengkulu. Diharapkan petugas kesehatan dapat meningkatkan program pelaksanaan program BPJS mulai dari tingkat pelayanan dasar sampai ketingkat pelayanan rujukan menjadi lebih baik lagi.
\end{abstract}

Kata Kunci : Usia, Pendidikan, Pekerjaan, Paritas dan Kepuasan ibu hamil

Angka kematian Ibu dan Bayi di Indonesia masih tergolong tinggi dibandingkan dengan Negara ASEAN lainnya. Hal ini dikarenakan oleh 3T (Terlambat mengambil keputusan, terlambat mendapatkan transportasi,dan terlambat penanganan di sarana pelayanan kesehatan). Berdasarkan hasil survei Demografi Kesehatan Indonesia (SDKI) pada tahun 2007 angka kematian ibu mencapai 228 per 100.000 kelahiran hidup. Menurut data Survei Demografi
Kesehatan Indonesia (SDKI) tahun 2012 AKI tercatat sebesar 102/100.000 kelahiran hidup dan AKB sebesar 23/100.000 kelahiran hidup. Dalam rangka menurunkan Angka kematian Ibu dan Bayi. Selain meningkatkan cakupan persalinan ditenaga kesehatan juga sekaligus mempermudah akses pelayanan kesehatan sehingga diharapkan dapat mengurangi resiko kematian ibu dan bayi. Semakin mudahnya akses pelayanan kesehatan oleh masyarakat 
terutama sejak diberlakukannya JAMPERSAL yang diganti pada 1 Januari tahun 2014 ini dengan Program BPJS.

Berdasarkan data dari Dinas Kesehatan Kota Bengkulu tahun 2012 jumlah ibu hamil yang ada di wilayah Puskesmas Kota Bengkulu berjumlah 6856 orang dengan cakupan K1 berjumlah 6013 orang dan cakupan K4 berjumlah 5588. Hardiyanto (2010) menyatakan beberapa survei yang dilakukan oleh Lembaga Swadaya Masyarakat (LSM) salah satunya dilakukan oleh International Corruption Watch (ICW) menilai pelayanan kesehatan bagi masyarakat miskin melalui Program Jamkesmas belum optimal. LSM itu menyatakan meski hasil survei menunjukan sebagian besar peserta Jamkesmas $(83,2 \%)$ menyatakan puas dengan layanan yang diberikan namun masih ada peserta yang tidak puas dengan pelayanan dokter $(5 \%)$, perawat $(4,7 \%)$ dan petugas kesehatan sebanyak (4,7\%). Hasil observasi ICW juga menunjukan bahwa kualitas pelayanan kesehatan bagi peserta Jamkesmas belum baik. Hasil penelitian Soedjadi dalam Pujihastuti (2008) menyebutkan adanya perbedaan kepuasaan antara peserta Askes (Asuransi Kesehatan) dan peserta non askes yang membayar tunai di rumah sakit, seperti: (1) Prosedur berobat terlalu rumit, (2) Tidak ada informasi yang jelas tentang petunjuk berobat, (3) Fasilitas yang berhubungan dengan Askes dipersulit dengan kurangnya pelayanan, (4) Diskriminasi antara pasien Askes dan non Askes, sehingga banyak peserta yangtelah memiliki Kartu Askes lebih suka menjadi pasien non Askes dengan konsekuensi harus membayar, (5) Terlalu rumitnya prosedur pengambilan obat, contohnya bagi penderita penyakit kronis, pengambilan obat yang dimaksud harus diulang setiap 10 hari dengan proses yang sama, (6) Kurangnya pelayanan petugas apotik terhadap waktu tunggu yang terlalu lama karena petugas apotik cenderung mendahulukan pengambilan obat non Askes yang membayar tunai.

Bagaimana halnya dengan Program BPJS yang juga merupakan program Pemerintah di bidang kesehatan terkait jaminan persalinan yang diperuntukan bagi ibu hamil yang memiliki jaminan kesehatan BPJS agar dapat meng- akses pelayanan kesehatan baik di tingkat pertama maupun di tingkat lanjutan sesuai ketetapan. Tingkat kepuasan ibu hamil yang diukur dengan indeks kepuasan pasien berdasarkan prinsip pelayanan yang ditetapkan dalam keputusan Menpan no 25 tahun 2004 dengan 14 unsur dasar pengukuran pelayanan dan karakteristik ibu tentang umur, paritas, pekerjaan dan pendidikan. Berdasarkan latar belakang di atas, maka perlu dilakukan penelitian untuk mengidentifikasi Tingkat kepuasan Ibu hamil pengguna BPJS yang diselenggarakan oleh Puskesmas se Kota Bengkulu tahun 2014.

Berdasarkan latar belakang di atas masalah dalam penelitian ini tujuan penelitian ini adalah untuk mendeskrpsikan tingkat kepuasan ibu hamil terhadap pelaksanaan program BPJS di Puskesmas se-kota Bengkulu.

\section{BAHAN DAN CARA KERJA}

Penelitian ini dilaksanakan dengan metode surveianalitik dengan menggunakan rancangan potong silang, Populasi pada penelitian ini adalah seluruh Ibu hamil yang memeriksakan kehamilannya tahun 2014 di Puskesmas Kota Bengkulu berjumlah 6856 orang ibu hamil. Sampel dalam penelitian ini adalah ibu hamil yang berjumlah 113 orang yang diambil secara Accidental Sampling sampel (setiap Puskesmas 5-6 orang) di 20 Puskesmas Kota Bengkulu yang menggunakan Program BPJS. Semua Ibu hamil adalah pengguna BPJS yang datang periksahamil di Puskesmas se-Kota Bengkulu. Analisa data diolah secara análisis diskriftif dan diuji menggunakan análisis chisquare.

\section{HASIL}

Berdasarkan Tabel 1 dapat disimpulkan bahwa sebagian besar ibu hamil pelanggan BPJS adalah berusia muda, berpendidikan tinggi, lebih banyak yang bekerja, dengan paritas multi para dan lebih sebagian memuaskan layanan BPJS di Puskesmas seKota Bengkulu.

Berdasarkan tabel 2 analisis hubungan antara umur dengan kepuasan ibu hamil pelanggan BPJS hampir tidak ada perbedaan kepuasan pelanggan ibu hamil yang berusia muda dan 
usia dewasa dalam pelayanan BPJS, sehingga analisis X2 dapat disimpulkan bahwa tidak hubungan antara umur dengan kepuasan ibu pelanggan BPJS dengan nilai $\mathrm{p}=0,65$.

Tabel 1 Distribusi frekuensi responden berdasarkan umur, pendidikan, pekerjaan, paritas dan kepuasan pelanggan

\begin{tabular}{lcc}
\hline \multicolumn{1}{c}{ Variabel } & $\begin{array}{c}\text { Frekuensi } \\
(\boldsymbol{n}=\mathbf{1 1 5})\end{array}$ & Persentase \\
\hline Umur & & \\
Usia muda & 94 & 81,7 \\
Usia Dewasa & 21 & 18,3 \\
$\begin{array}{l}\text { Pendidikan } \\
\text { Rendah }\end{array}$ & & \\
Tinggi & 32 & 27,8 \\
Pekerjaan & 83 & 72,2 \\
$\begin{array}{l}\text { Bekerja } \\
\text { Tdk bekerja }\end{array}$ & & \\
Paritas & 55 & 47,8 \\
Primi & 60 & 52,2 \\
Multi & & \\
Kepuasan pelanggan & 40 & 34,8 \\
Tdk Memuaskan & 75 & 65,2 \\
Memuaskan & & \\
\hline
\end{tabular}

Tabel 2 Hubungan umur dengan kepuasan ibu hamil pengguna BPJS di Puskesmas se-Kota Bengkulu Tahun 2014

\begin{tabular}{|c|c|c|c|c|c|c|c|}
\hline \multirow{3}{*}{ Umur } & \multicolumn{4}{|c|}{ Kepuasan } & & & \multirow{3}{*}{$\mathbf{p}$} \\
\hline & \multicolumn{2}{|c|}{$\begin{array}{c}\text { Tdk } \\
\text { Memuas- } \\
\text { kan }\end{array}$} & \multicolumn{2}{|c|}{$\begin{array}{l}\text { Memuas- } \\
\text { kan }\end{array}$} & \multicolumn{2}{|c|}{ Total } & \\
\hline & $\mathbf{n}$ & $\%$ & $\mathbf{n}$ & $\%$ & $\mathbf{n}$ & $\%$ & \\
\hline \multicolumn{8}{|l|}{ Umur } \\
\hline Usia Muda & 37 & 39,4 & 57 & 60,6 & 94 & 100 & 0,65 \\
\hline Usia Dewasa & 10 & 47,6 & 11 & 52,4 & 21 & 100 & \\
\hline \multicolumn{8}{|l|}{ Pendidikan } \\
\hline Rendah & 15 & 46,9 & 17 & 53,1 & 32 & 100 & 0,54 \\
\hline Tinggi & 32 & 38,6 & 51 & 61,4 & 83 & 100 & \\
\hline \multicolumn{8}{|l|}{ Pekerjaan } \\
\hline Bekerja & 22 & 40 & 33 & 60 & 55 & 100 & 1 \\
\hline Tidak Bekerja & 25 & 41,7 & 35 & 58,3 & 60 & 100 & \\
\hline \multicolumn{8}{|l|}{ Paritas } \\
\hline Primi & 11 & 27,5 & 29 & 72,5 & 40 & 100 & 0,05 \\
\hline Multi & 36 & 48 & 39 & 52 & 75 & 100 & \\
\hline
\end{tabular}

Berdasarkan tabel 2 terdapat bahwa responden yang mempunyai pendidikan tinggi mendapatkan pelayanan yang memuaskan dari BPJS dibandingkan dengan responden yang mempunyai pendidikan yang rendah, sedangkan hasil uji X 2 menyatakan tidak ada hubungan antara pendidikan dengan kepuasan ibu hamil pelanggan BPJS dengan nilai $\mathrm{p}=0,54$. Hampir tidak ada perbedaan kepuasan pelanggan pengguna BPJS terhadap ibu bekerja dan ibu tidak bekerja, hasil analisis X2dapat disimpulkan bahwa tidak hubungan antara pekerjaan dengan kepuasan ibu pengguna BPJS dengan nilai $p=1$.

Berdasarkan Tabel 3 hampir tidak ada perbedaan kepuasan antara ibu hamil primi dan multi, analisis X2 dapat disimpulkan bahwa ada hubungan antara paritas dengan kepuasan ibu pengguna BPJS dengan nilai $\mathrm{p}=0,05$.

\section{PEMBAHASAN}

\section{Hubungan Umur dengan kepuasan ibu hamil pengguna BPJS}

Hasil penelitian menunjukkan bahwa hampir tidak ada perbedaan kepuasan pengguna program BPJS pada ibu hamil yang berusia muda dan berusia dewasa, uji statistik menunjukkan tidak ada hubungan antara usia dengan kepuasan ibu hamil pengguna program BPJS tahun 2014. Hasil penelitian ini sejalan dengan penelitian yang dilakukan di PKM dan RSU dr. Pirngadi Medan tahun 2014 dimana pengguna Jamkesmas yang datang berkunjung dengan persentase terbesar pada usia dewasa $(25,3 \%)$ berikutnya berusia muda (18,0\%). Umur merupakan salah satu variabel dari model demografi yang digunakan sebagai ukuran mutlak atau indikator psikologi yang berbeda, umur ibu mempengaruhi bagaimana ibu hamil mengambil keputusan dalam pemeliharaan kesehatan (Notoatmodjo, 2002). Semakin cukup umur, tingkat kematangan dan kekuatan seseorang akan lebih matang dalam berfikir dan bekerja (Notoatmodjo, 2002), Perubahan yang terjadi pada ibu biasa juga akan mempengaruhi psikologis ibu dalam bertindak, berbuat dalam menerima respon yang ada di sekitar lingkungan, maka usia dapat mempengaruhi kematangan ibu hamil dan juga akan mempengaruhi dalam menerima kepuasan dalam pelayanan yang diberikan oleh tenaga kesehatan dalam program BPJS.

Penelitian ini dapat disimpulkan bahwa usia muda yang berkunjung ke Puskesmas untuk mendapatkan program BPJS lebih banyak dibandingkan dengan usia dewasa, dan persentase usia dewasa yang berkunjung untuk mendapatkan pelayanan program BPJS seimbang antara yang mengatakan puas dan tidak puas dalam mendapatkan pelayanan program BPJS, sehingga dalam penelitian ini tidak terbukti 
bahwa usia berhubungan dengan kepuasan ibu hamil pengguna program BPJS.

\section{Hubungan Pendidikan dengan Kepuasan Ibu Hamil Pengguna Program BPJS}

Hasil penelitian menunjukkan bahwa ibu hamil yang mempunyai pendidikan tinggi lebih dari sebagian mengatakan puas dengan pelayanan BPJS dibandingkan dengan respon-den yang mempunyai pendidikan rendah, sedangkan hasil uji nilai $\mathrm{p}=0,54$ dapat disim-pulkan bahwa tidak ada hubungan antara pendidikan dengan kepuasan ibu hamil pengguna program BPJS.

Hasil penelitian yang dilakukan di puskesmas dan RSU dr. Pringadi Medan tahun 2014 dimana pengguna Jamkesmas yang datang berkunjung dengan persentase yang seimbang antara pengguna Jamkesmas pendidikan rendah dan pendidikan tinggi $(50,7 \%)$ dan $(49,3 \%)$, sedangkan pada penelitian ini pengguna program BPJS lebih tinggi pada responden dengan pendidikan tinggi $(72,2 \%)$. Hal ini disebabkan bahwa program BPJS saat ini dipungut iuran setiap bulan, sehingga responden dengan pendidikan rendah akan lebih sedikit berkunjung untuk menggunakan program BPJS, sementara untuk jatah rakyat miskin masih terbatas.

Dari hasil penelitian ini dapat disimpulkan bahwa tingkat pendidikan tidak mempengaruhi kepuasan pelayanan yang diberikan, namun secara teori kepuasan pelanggan dipengaruhi oleh tingkat pendidikan, kelemahan penelitian ini terletak pada jumlah sampel yang ibu hamil pengguna program BPJS dengan tingkat pendidikan rendah hanya sedikit yang berkunjung ke Puskesmas $(27,8 \%)$.

Hubungan Pekerjaan dengan kepuasan ibu hamil pengguna program BPJS

Berdasarkan hasil penelitian hampir tidak ada perbedaan jumlah kunjungan antara ibu

\section{DAFTAR RUJUKAN}

Ary, 2011. Rumah Sakit Bersalin di Gandeng Kelola Jampersal, (Online), http://www.malang-post.com, diakses 29 September 2011).

Data Statistik Indonesia. 2011. Survei Demografi Kesehatan Indonesia (SDKI) Tahun 20022003.(Online) http://www.data statistikIndonesia.com, diakses tanggal 23 April 2011. bekerja $(47,8 \%)$ dan ibu tidak bekerja $(52,2 \%)$, sedangkan hasil analisis bivariat hampir tidak perbedaan kepuasan pelanggan pengguna program BPJS terhadap ibu bekerja dan ibu tidak bekerja, hasil analisis dapat disimpulkan bahwa tidak hubungan antara pekerjaan dengan kepuasan ibu pengguna BPJS dengan nilai $\mathrm{p}=1$.

Hasil penelitian ini sejalan dengan penelitian yang dilakukan di PKM dan RSU dr. Pringadi Medan tahun 2014 dimana pengguna Jamkesmas yang datang berkunjung dengan persentase terbesar pada ibu hamil yang bekerja $(57,3 \%)$ berikutnya yang tidak bekerja $(42,7 \%)$. Ibu hamil yang bekerja yang berkunjung ke Puskesmas untuk menggunakan program BPJS lebih sedikit dibandingkan dengan ibu hamil yang tidak bekerja, hal ini dikarenakan ibu yang bekerja tidak berkujung menggunakan program BPJS pada pagi hari, sedangkan penelitian ini dilakukan ibu hamil pengguna program BPJS pagi hari. Dari penelitian ini dapat disimpulkan bahwa tidak ada hubungan anatara pekerjaan ibu hamil dengan kepuasan pengguna program BPJS di Puskesmas se-Kota Bengkulu.

\section{KESIMPULAN}

Berdasarkan penelitian yang dilakukan tentang Kepuasan layanan ibu hamil pengguna program BPJS di Puskesmas se-Kota Bengkulu Tahun 2014 dapat disimpulkan sebagai berikut : Tidak ada hubungan usia, pendidikan, pekerjaan ibu hamil pengguna program BPJS dengan kepuasan layanan Puskesmas, dan ada hubungan paritas ibu hamil pengguna program BPJS dengan kepuasan layanan Puskesmas se-Kota Bengkulu Tahun 2014. Saran bagi petugas Kesehatan di Puskesmas dapat meningkatkan pelayanan yang belum baik dan mempertahankan kondisi yang sudah baik dalam memberikan layanan pada ibu hamil pengguna program BPJS.

Kemenkes Republik Indonesia. 2004. Undang-Undang Nomor 40 Tahun 2004 Tentang Sistem Jaminan Sosial Nasional

Kemenkes Republik Indonesia. 2009. Undang-Undang Nomor 36 Tahun 2009 Tentang Kesehatan

Kemenkes Republik Indonesia. 2009. Undang-Undang Nomor 44 Tahun 2009 Tentang Rumah Sakit 
138 Jurnal Media Kesehatan, Volume 8 Nomor 2, Oktober 2015, hlm 100-204

Kemenkes Republik Indonesia. 2011. Petunjuk Teknis Jaminan Persalinan. Jakarta.

Kemenkes Republik Indonesia. 2011. Undang-Undang Nomor 24 Tahun 2011 Tentang Badan Penyelenggara Jaminan Sosial

Kemenkes Republik Indonesia. 2012. Peraturan Pemerintah Nomor 101 Tahun 2012 Tentang Penerima Bantuan Iuran Jaminan Kesehatan

Kemenkes Republik Indonesia. 2012. Peta Jalan Menuju Jaminan Kesehatan Nasional 2012-2019, Republik Indonesia

Kemenkes Republik Indonesia. 2013. Buku Pegangan Sosialisasi Jaminan Kesehatan Nasional (JKN) dalam Sistem Jaminan Sosial Nasional, Kementerian Kesehatan Republik Indonesia
Kemenkes Republik Indonesia. 2013. Peraturan Presiden Nomor 12 Tahun 2013 tentang Jaminan Kesehatan Nasional, Republik Indonesia

Purwanto, 2007. Kamus Besar Bahasa Indonesia. Jakarta: Balai Pustaka.

Subagyo, 2011. Jaminan Persalinan, Angka Kematian Ibu dan KB, (Online), http://www.KBR68H.com , diakses 23 April 2011).

Supardi, 2008. Faktor-faktor yang Berhubungan dengan Kepuasan Pasien Rawat Jalan dan Rawat Inap di Puskesmas. Badan Litbangkes Depkes RI. (Online) http://Apotekputer,com diakses tanggal 3 Januari 2012). 